\title{
Fast detection technique for voltage unbalance in three-phase power system
}

\author{
Ibrahim I. Al-Naimi ${ }^{1}$, Jasim A. Ghaeb ${ }^{2}$, Mohammed J. Baniyounis ${ }^{3}$, Mustafa Al-Khawaldeh ${ }^{4}$ \\ ${ }^{1}$ Electrical and Computer Engineering Department, Collage of Engineering, Sultan Qaboos University, Muscat, Oman \\ ${ }^{2}$ Electrical Engineering Department, Faculty of Engineering, Philadelphia University, Amman, Jordan \\ ${ }^{3,4}$ Mechatronics Engineering Department, Faculty of Engineering, Philadelphia University, Amman, Jordan
}

\begin{tabular}{l} 
Article Info \\
\hline Article history: \\
Received May 17, 2021 \\
Revised Sep 3, 2021 \\
Accepted Sep 13, 2021 \\
\hline
\end{tabular}

\section{Keywords:}

Power distribution

Power quality

Space vector

Voltage unbalance

\begin{abstract}
In this paper, the problem of voltage unbalance in the three-phase power systems is examined. A fast detection technique (FDT) is proposed to detect the voltage unbalance precisely and speedily. The well-known detection methods require more than one cycle time to detect the unbalanced voltages, whereas the proposed technique detects the unbalanced situations speedily in a discrete manner. Reducing the time duration required to detect the unbalanced voltages will enhance the dynamic response of the control system used to balance these voltages. The FDT acquires the instantaneous values of the three load voltages, calculates the sum and the space vector for these voltages at each sample, and utilizes these parameters to detect the voltage unbalance accurately within a quarter of the cycle time. A proof-of-concept simulation model for a real power system has been built. The parameters of the aqaba-qatrana-south amman (AQSA) Jordanian power system are considered in the simulation model. Also, several test cases have been conducted to test and validate the capabilities of the proposed technique.
\end{abstract}

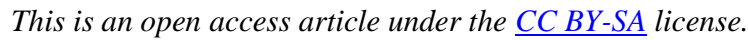

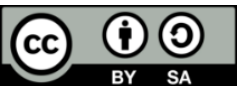

\section{Corresponding Author:}

Ibrahim Izziddin Al-Naimi

Electrical and Computer Engineering Department

Sultan Qaboos University

Al Khod, Muscat OM, 123, Oman

Email: i.alnaimi@squ.edu.om

\section{INTRODUCTION}

The three-phase power systems suffer from different challenging problems, e.g., unbalanced voltages at the load side [1]-[3]. The voltage unbalance usually degrades the power quality of the electrical system [4], [5]. As a result, the U.S. economy loses between 15 to 24 billion dollars a year in power quality problems [6]. In modern buildings, the frequent use of photovoltaics (PVs), battery storages, and charging stations for electric vehicles (EV) intensify the voltage unbalance problem [4], [7]. Additionally, the malfunctions of the electrical equipment in the power distribution systems normally lead to unbalanced voltages [8]. In general, the voltage unbalance in electrical power systems is resulted from either unbalanced loads or asymmetries in network topology [9]. In most practical cases, the unregulated distribution of loads is the main factor that causes the unbalanced voltages [10]. Subsequently, the volt-amperes of the three lines between the generator and the load become different, and thus generating unbalanced voltages at the load side. Maintaining balanced voltages at the load side is not always possible. This is due to the frequent connection and disconnection of the loads and the uneven load distribution between the three-phases [11]. Therefore, changing the system configuration through the feeder switching operations may balance the electrical power distributions. This operation is based on allocating single-phase loads equally across the three-phase system. 
Dissimilar inter-stage coupling of impedances and asymmetrical transformer windings normally lead to network asymmetries [12], [13]. It is challenging to detect the sources that cause voltage unbalance, especially in the power interconnected networks containing untransposed transmission lines and unbalanced loads. Many problems are associated with the voltage unbalance, such as excessive energy losses, heating up the system equipment, and the possibility of system instability [14]-[16]. The effect of the unbalanced voltages appears clearly on three-phase motors [17], [18]. The inversely rotating magnetic field of the negative-sequence system causes a negative braking torque. This torque has to be subtracted from the base torque and thus weakening the machine torque. In addition, the excessive power losses and the heating due to unbalance conditions will reduce the efficiency of the induction motor [19]. The voltage unbalance creates adverse effects on electrical equipment. The efficiency of transformers, cables, or lines is reduced due to the negative sequence components in which the equipment operating limits are determined by the RMS rating current [20]. Additionally, the unbalanced conditions of power converters produce characteristic and uncharacteristic harmonics [9], [21].

Employing the static volt-ampere-reactor compensation (SVC) in the electric power system provides many advantages such as voltage regulation and load balancing, and also enhances the system stability [22][24]. To balance three-phase load currents, the SVC needs to absorb a particular amount of positive or negative reactive power to produce zero resultant reactive power at the SVC load common point [25]. However, the unbalance conditions of SVC will generate uncharacteristic harmonics. This will generate more power losses in the power system transmission lines. To reduce the power outage duration, the restoration of faulted lines or load changes should be achieved quickly. Additionally, the dynamic response of the controller used to balance the three-phase voltages needs to be enhanced by reducing the time duration required to detect the unbalanced voltages. In this work, the three load voltages are acquired intermittently to determine the voltage unbalance speedily. The detection of voltage unbalance is based on calculating the sum $\left(\mathrm{V}_{\text {sum }}\right)$ and the space vector $\left(\mathrm{V}_{\text {space }}\right)$ of the three load voltages at each sample. The $\mathrm{V}_{\text {sum }}$ and $\mathrm{V}_{\text {space }}$ parameters are utilized by a novel algorithm to detect the voltage unbalance quickly and precisely.

The paper is organized as follows: Section 2 represents a literature review of similar work. Section 3 introduces the three-phase unbalance electric power system. The discrete data measurements are discussed in sections 4 and 5. The proposed fast detection technique (FDT) is introduced in section 6. Section 7 represents the effect of unbalanced load changes and unsymmetrical power system faults on the three load voltages, together with the simulated results. Finally, conclusions are introduced in section 8 .

\section{LITERATURE REVIEW}

To study the unbalance voltage in a three-phase electrical power system, the so-called Fortescue components or symmetrical components are employed [26]. In this method, the three-phase system is decomposed into positive-sequence, negative-sequence, and zero-sequence subsystems. The voltage unbalance is defined by National Electrical Manufacturers Association (NEMA) as maximum deviation from the average of three-line voltages, referred to the average of three-line voltages [14], [27] Furthermore, it is defined in IEEE Std.936-1987 as the difference between the highest and the lowest RMS voltages, referred to the average RMS of the three voltages [28]. The IEEE Std.1159-1195 provides the confirmed true definition, which is the ratio between the negative-sequence and the positive-sequence voltages [29]. It is recommended that the voltage unbalance for AC motors do not exceed 1\% [14]. If a motor with $94.4 \%$ efficiency, 1800 RPM, and $100 \mathrm{hp}$ is operating at $2.5 \%$ unbalance conditions, the motor efficiency will reduce to $93 \%$ [14].

The space vector (SV) converts the effect of the three instantaneous values for the three-phase quantities into a rotating two-axis complex plane [30], [31]. This property of the SV is employed in the threephase systems to convert the analysis into a stationary state of $\alpha-\beta$ axis. This will simplify the analysis of the three-phase electric power system. A space vector modulation method is employed in three-phase inverters to improve the inverter's output by generating fewer harmonics [24], [32], [33]. Furthermore, the space vector was used in the author's prior work for voltage regulation [34].

Many research efforts have been directed toward detecting and solving the voltage unbalance problems in the three-phase electrical network. Paranavithana and Perera [12] assigned the location of individual lines causing voltage unbalance, by determining the line coupling impedance between the positive and negative sequence networks. Sun et al. O'Rouke et.al, [35], [36] developed an algorithm for voltage unbalance detection based on Clark transformation. In this algorithm, the three voltages are converted to $\alpha-\beta$ stationary system. However, by using this method, the voltage unbalance can be detected after a complete cycle time, which is 20 milliseconds in a $50 \mathrm{~Hz}$ power system. The unbalanced three-phase supply voltages may exist in the power distribution system. The calculation of the voltage unbalance factor (VUF) was obtained through the transformation of voltage phasors in a three-phase power system into simple trigonometric equations [37]. This method reduced the number of parameters used in the calculation process, 
leading to fewer clock cycles for VUF calculation. Chen et al. [38], the VUF is defined as the ratio of negative sequence to positive sequence voltages. The time needed to calculate the negative and positive sequence voltages is one cycle time. Additional half-cycle time is needed to calculate the VUF. Consequently, by using this method, voltage unbalance can be detected after one and a half cycle time which is 30 milliseconds in a $50 \mathrm{~Hz}$ power system.

Shigenobu et al. [39] suggested a developed mathematical approach to detect the voltage unbalance precisely in different conditions. In this approach, an additional VUF is calculated based on the zerosequence voltage in the symmetrical component method. Accordingly, by using this method, voltage unbalance can be detected after one and a half cycle time. Girigoudar et al. [40] suggested using three metrics to detect the unbalance voltages accurately in power systems, namely, VUF, phase-voltage unbalance rate (PVUR), and line-voltage unbalance rate (LVUR). Although this method will minimize the effect of unbalance voltages according to different metrics, it needs a relatively higher exciting time (i.e., more than one and a half cycle time). Ghijselen et al. [41], the percentage of VUF is determined directly from the three RMS line voltages. The triangle of three unequal voltages is divided into two equilateral triangles, in which the triangle side lengths are the positive and negative sequence voltages. Therefore, a complete cycle is needed to calculate the voltage unbalance using this definition. Sawitri et al. [42] Okelola et al. [43] applied the support vector machine (SVM) and neural network (NN) respectively to detect the voltage unbalance in induction motors. Additionally, Alkayyati et al. [44], [45] employed optimization with machine learning techniques to solve the unbalance problem in electrical power systems.

\section{THREE-PHASE UNBALANCE SYSTEM}

The three-phase power systems are ideally balanced, and the related distribution systems are designed carefully to guaranty the overall balance in the three phases. For any balanced electric power system, the three voltages are equal in magnitude and out-of-phase by $2 \pi / 3 \mathrm{rad}$. It is important to keep the system voltage within specific limits at different points throughout the power system. Different kinds of large disturbances (e.g., transmission line faults and sudden load changes) normally distort the performance of the electrical power system, such as the voltage balance. In other words, unsymmetrical faults in the transmission lines or unbalanced load changes will directly affect the balance of the three-phase system and produce unbalanced currents and voltages. Consequently, three components will be generated, namely, zero-sequence, positive-sequence, and negative-sequence components $\left(\vec{V}_{0}, \vec{V}_{1}, \vec{V}_{2}\right)$. By considering the operator (a), each one of the three unbalanced voltages $\left(\vec{V}_{a}, \vec{V}_{b}, \vec{V}_{c}\right)$ can be written in terms of the three sequence components $\left(\vec{V}_{0}\right.$, $\overrightarrow{\mathrm{V}}_{1}, \overrightarrow{\mathrm{V}}_{2}$ ) as shown in (1) [46].

$$
\left[\begin{array}{l}
\vec{V}_{a} \\
\vec{V}_{b} \\
\vec{V}_{c}
\end{array}\right]=\left[\begin{array}{lll}
1 & 1 & 1 \\
1 & \mathrm{a}^{2} & \mathrm{a} \\
1 & \mathrm{a} & \mathrm{a}^{2}
\end{array}\right]\left[\begin{array}{l}
\vec{V}_{0} \\
\vec{V}_{1} \\
\vec{V}_{2}
\end{array}\right]=A\left[\begin{array}{l}
\vec{V}_{0} \\
\vec{V}_{1} \\
\vec{V}_{2}
\end{array}\right]
$$

Where the rotation operator $a$ is given by: $\mathrm{a}=\mathrm{e}^{j \frac{2 \pi}{3}}$, The inverse of the matrix (A) is given by:

$$
A^{-1}=\frac{1}{3}\left[\begin{array}{lll}
1 & 1 & 1 \\
1 & \mathrm{a} & \mathrm{a}^{2} \\
1 & \mathrm{a}^{2} & \mathrm{a}
\end{array}\right]
$$

Multiplying (1) by $\left(\mathrm{A}^{-1}\right)$ gives the three sequence components as shown in (2).

$$
\left[\begin{array}{l}
\vec{V}_{0} \\
\vec{V}_{1} \\
\vec{V}_{2}
\end{array}\right]=\frac{1}{3}\left[\begin{array}{lll}
1 & 1 & 1 \\
1 & \mathrm{a} & \mathrm{a}^{2} \\
1 & \mathrm{a}^{2} & \mathrm{a}
\end{array}\right]\left[\begin{array}{l}
\vec{V}_{a} \\
\vec{V}_{b} \\
\vec{V}_{c}
\end{array}\right]
$$

In this work, both the sum and the space vector of the three voltages are calculated at each sample and utilized to detect the voltage unbalance quickly. The zero-sum of the three instantaneous voltages is not a clear indication of voltage balance. Hence, the calculation of space vector is required to ensure precise detection of unbalanced voltages. The space vector $\left(\vec{V}_{\text {space }}\right)$ depends on the three instantaneous voltages and can be calculated as shown in (3) [46]. For balanced conditions, the magnitude of the space vector is fixed at any instant of time. 


$$
\vec{V}_{\text {space }}=\mathrm{a}^{0} v_{a(t)}+\mathrm{a}^{1} v_{b(t)}+\mathrm{a}^{2} v_{c(t)}
$$

\section{DISCRETE DATA MEASUREMENT}

In this work, measurements of discrete data are employed to acquire different variables of the AQSA Jordanian electrical power system at a discrete-time, i.e., samples $\mathrm{f}\left(\mathrm{kT}_{\mathrm{s}}\right)$, where $\mathrm{T}_{\mathrm{s}}$ is the sampling period and $\mathrm{k}$ is an integer with the range $1 \leq \mathrm{k} \leq 20$. The three load voltages are measured at the sample. Besides, the space vector value and the sum of these voltages should be calculated to detect the voltage unbalance quickly and precisely. The number of samples per cycle (ns) is given by (4).

$$
n s=\frac{T}{T_{S}}
$$

Where:

- $\mathrm{T}$ is the cycle time, which equals $0.02 \mathrm{sec}$ in $50 \mathrm{~Hz}$ power system.

- Ts is the sampling period, which equals $1 \mathrm{~ms}$ for 20 samples/cycle in $50 \mathrm{~Hz}$ power system.

In general, the balanced three-phase variables $v_{a}, v_{b}$, and $v_{c}$ produce zero-sum at any instant of time. The space vector for each of the three voltages $v_{a}, v_{b}$, and $v_{c}$ is the corresponding variable on its axis at the aaxis of operator $\mathrm{a}^{0}, \mathrm{~b}$-axis of operator $\mathrm{a}^{1}$, and $\mathrm{c}$-axis of operator $\mathrm{a}^{2}$. The total value of the space vector in a balanced condition is fixed at all instants of time. The properties of the space vector and the sum of the three voltages are used in this work to determine the voltage unbalance in a very short time.

\section{THE SUM OF THE THREE INSTANTANEOUS LOAD VOLTAGES}

The sum of any three balanced voltages is zero. For the three-phase power system shown in Figure 1, the three-phase load voltages are given by (5).

$$
\begin{aligned}
\vec{V}_{\mathrm{abL}} & =\overrightarrow{\mathrm{V}}_{\mathrm{AB}}-\overrightarrow{\mathrm{I}}_{a} \cdot \mathrm{Z}_{\mathrm{TTa}}+\overrightarrow{\mathrm{I}}_{b} \cdot \mathrm{Z}_{\mathrm{TTb}} \\
\vec{V}_{\mathrm{bcL}} & =\overrightarrow{\mathrm{V}}_{\mathrm{BC}}-\overrightarrow{\mathrm{I}}_{b} \cdot \mathrm{Z}_{\mathrm{TTb}}+\overrightarrow{\mathrm{I}}_{c} \cdot \mathrm{Z}_{\mathrm{TTc}} \\
\vec{V}_{\mathrm{caL}} & =\overrightarrow{\mathrm{V}}_{\mathrm{CA}}-\overrightarrow{\mathrm{I}}_{c} \cdot \mathrm{Z}_{\mathrm{TTc}}+\overrightarrow{\mathrm{I}}_{a} \cdot \mathrm{Z}_{\mathrm{TTa}}
\end{aligned}
$$

Where:

- $\vec{V}_{\mathrm{abL}}, \vec{V}_{\mathrm{bcL}}, \vec{V}_{\mathrm{caL}}$ : Load voltages.

- $\vec{V}_{\mathrm{AB}}, \vec{V}_{\mathrm{BC}}, \vec{V}_{\mathrm{CA}}$ : Balanced source voltages.

- $Z_{\mathrm{TTa}}, Z_{\mathrm{TTb}}, Z_{\mathrm{TTc}}$ : Transmission line and transformer impedances of phases a, b, and c

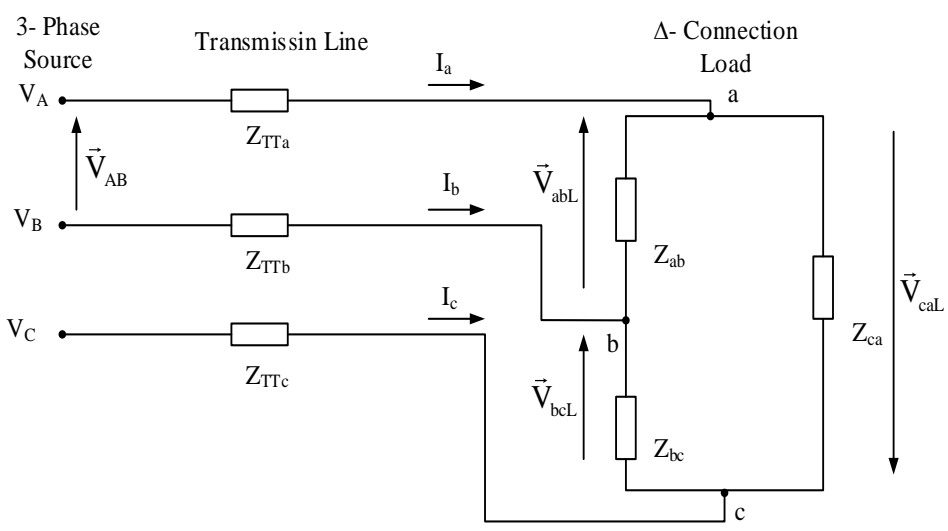

Figure 1. Three-phase power system

In this work, the sum of the three instantaneous load voltages $\left(\mathrm{V}_{\text {sum }}\right)$ is calculated for different cases of load changes (i.e., balanced and unbalanced load changes). The results are simulated for a signal frequency of $50 \mathrm{~Hz}$ and 21 samples per cycle. The load changes are applied at the instant $\mathrm{t}=0.05 \mathrm{sec}$ (i.e., at the sample number 50). Figure 2 (a) shows the response of the load currents caused by a balanced change in the threephase loads. This change caused a variation of $24.2 \%$ of the average inductive load current. The response of 
the three load voltages and the sum of their instantaneous values at different samples are shown in Figures 2 (b) and (c) respectively. Figure 3 (a) shows the response of the load currents caused by an unbalanced change in the three-phase load. This change caused a variation of $38.6 \%$ of the average inductive load current. The three load voltages and the sum of their instantaneous values at different samples are shown in Figures 3 (b) and 3 (c) respectively. Zero-sum of the three load voltages is obtained for both balanced and unbalanced load changes as shown in Figures 2 (c) and 3 (c). Figure 4 (a) shows the load currents caused by an unbalanced fault in the power system impedance, causing an average variation of $14.3 \%$ in load current. The response of the three load voltages is shown in Figure 4 (b). The instantaneous sum of three load voltages is not always zero (i.e., varies with time) as shown in Figure 4 (c). It has a sinusoidal form.

follows:

According to the results shown in Figures 2 (c), 3 (c), and 4 (c), two different cases are discussed as

- Case (1): The balanced and unbalanced changes in the three-phase load produce three-line currents. By substituting these currents in (5), the sum of the three instantaneous load voltages $\mathrm{V}_{\text {sum }}$ is always equal to zero as shown in (6). It is concluded that the balanced and unbalanced changes in the three-phase load, without changing the impedance of the power system $\left(\mathrm{Z}_{\mathrm{TT}}\right)$, will always produce zero-sum of the three load voltages, as shown in Figures 2 (c) and 3 (c)

$$
v_{a b L(t)}+v_{b c L(t)}+v_{c a L(t)}=0
$$

- Case (2): If there is a change in the impedance $\left(\mathrm{Z}_{\mathrm{TT}}\right)$ of the power system, e.g., the impedance $Z_{\mathrm{TTa}}$ is changed to $Z_{\mathrm{TTa}}^{\prime}$, the instantaneous load voltage $v_{a b L(t)}$ is changed to $v_{a b L(t)}^{\prime}$ and $v_{c a L(t)}$ to $v_{c a L(t)}^{\prime}$, leading to (7). It is concluded that the sum of three instantaneous load voltages $V_{\text {sum }}$ due to a fault in the power system impedance is not necessarily equal to zero. In this case, $\mathrm{V}_{\text {sum }}$ has a sinusoidal shape as shown in Figure 4 (c).

$$
v_{a b L(t)}^{\prime}+v_{b c L(t)}+v_{c a L(t)}^{\prime} \neq v_{a b L(t)}+v_{b c L(t)}+v_{c a L(t)}
$$

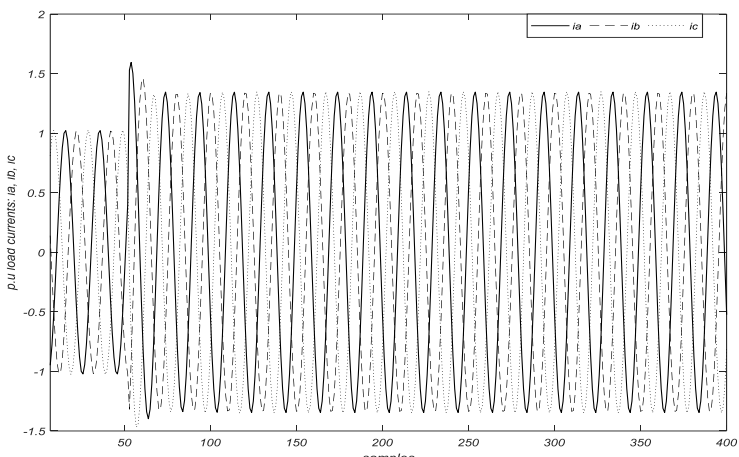

(a)

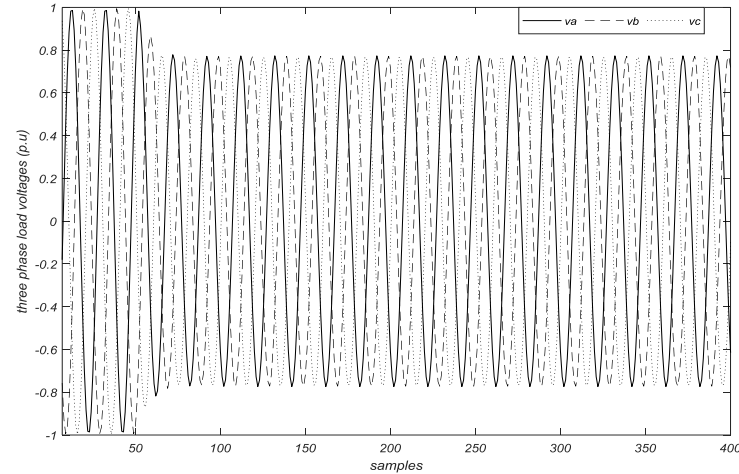

(b)

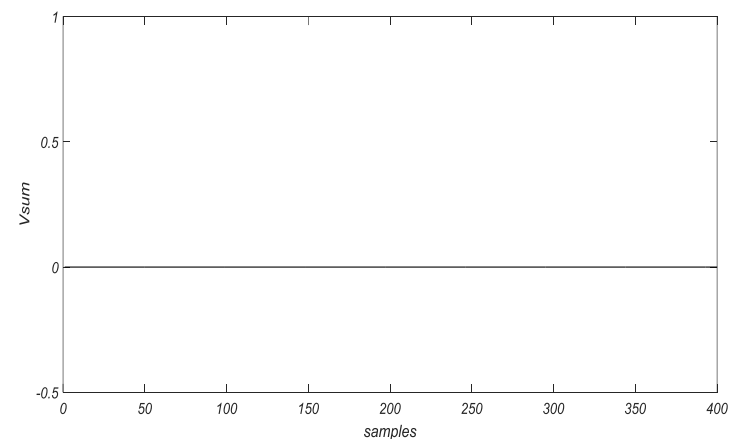

(c)

Figure 2. Results for a balanced change in the three-phase load, caused by injection of $24.2 \%$ of the average inductive load current, (a) the p.u load currents, (b) the p.u load voltages, (c) the Sum of p.u instantaneous load voltages 


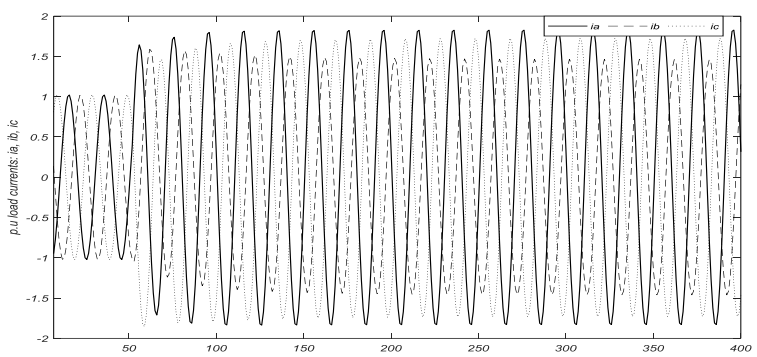

(a)

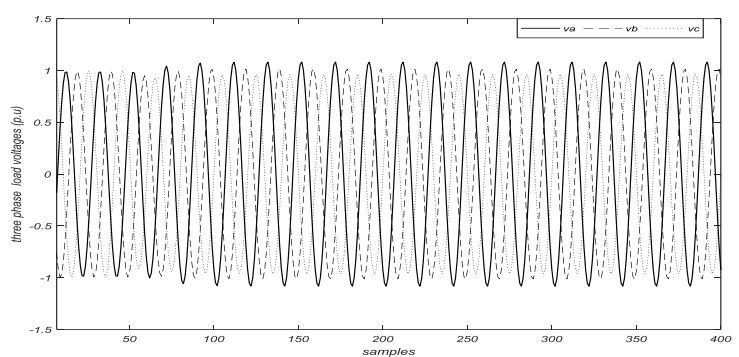

(b)

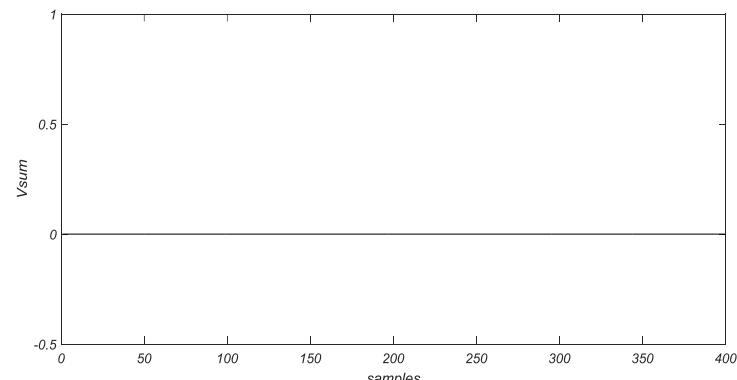

(c)

Figure 3. Results for unbalanced change in the threephase load, caused by rejection of $38.6 \%$ of the average inductive load current, (a) the p.u load currents, (b) the p.u load voltages, (c) the sum of p.u instantaneous load voltage

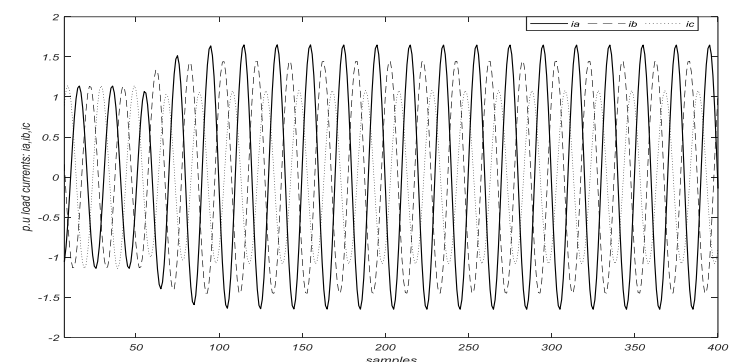

(a)

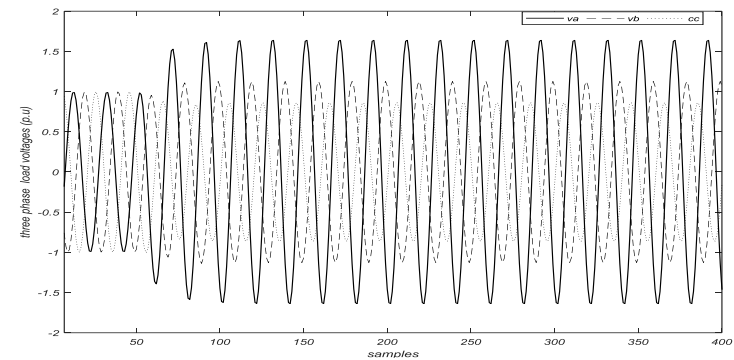

(b)

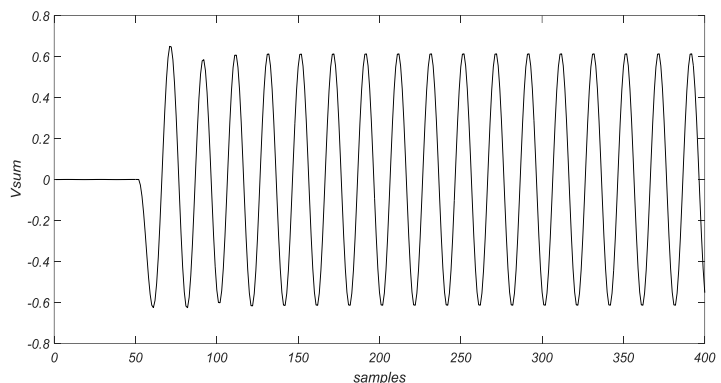

(c)

Figure 4. Results for unbalanced fault in power system, causing an average variation of $14.3 \%$ in load current, (a) the p.u load currents, (b) the p.u load voltages, (c) the sum of p.u instantaneous load voltages

\section{FAST DETECTION TECHNIQUE}

A balanced power system produces a balanced voltage throughout the electrical system line. The sum of the three instantaneous voltages is zero at any instant of time. Moreover, the space vector is fixed at these instants of time. In this work, a FDT is developed to detect the voltage unbalance speedily. In the FDT, the cycle time of the $50 \mathrm{~Hz}$ system is divided into 21 samples. The space vector $\left(\mathrm{V}_{\text {space }}\right)$ and the sum $\left(\mathrm{V}_{\text {sum }}\right)$ of the three load voltages are calculated at each sample. The proposed technique monitors the behavior of both $\mathrm{V}_{\text {space }}$ and $\mathrm{V}_{\text {sum }}$ for 5 consecutive samples and then applies predefined conditions to detect the unbalanced voltages. Consequently, only a quarter of the cycle time is needed to detect the voltage unbalance precisely.

The AQSA Jordanian power system is considered and modeled in this paper as a real case study to validate the proposed technique. Figure 5 shows the one-line diagram of the AQSA power System. South Amman Station is connected to the Aqaba Station through a $328 \mathrm{~km}$ transmission line of $400 \mathrm{kV}$. The 373 MW Qatrana substation lies between South Amman and Aqaba stations. South Amman station distributes about $800 \mathrm{MW}$ through the $400 \mathrm{k} \mathrm{V}-11 \mathrm{kV}$ multistage transformations to different loads [47]. To guarantee accurate and real system response, the AQSA transmission line is represented in the simulation by three nominal pi-sections. The Aqaba-Qatrana transmission line of $245 \mathrm{~km}$ is divided into two pi-sections, while the Qatrana- South Amman transmission line of $83 \mathrm{~km}$ is represented by one pi-section. In this work, the authors have developed the FDT to detect the voltage unbalance accurately and in short time. If there is a change in the system, the FDT provides the three following conditions: 
- Condition (1): If the calculated sum of the three instantaneous load voltages $\left(\mathrm{V}_{\text {sum }}\right)$ is zero and the calculated space vector $\left(\mathrm{V}_{\text {space }}\right)$ is fixed for the predefined samples, the change is balanced and occurred in the load impedance.

- Condition (2): If the calculated sum of the three instantaneous load voltages $\left(\mathrm{V}_{\text {sum }}\right)$ is zeros and the calculated space vector $\left(\mathrm{V}_{\text {space }}\right)$ is varied in sinusoidal form for the predefined samples, the change is unbalanced and occurred in the load impedance.

- Condition (3): If both the calculated sum of the three instantaneous load voltages $\left(\mathrm{V}_{\text {sum }}\right)$ and the calculated space vector $\left(\mathrm{V}_{\text {space }}\right)$ are varied for the predefined samples, the fault is unbalanced and occurred in the power system equipment. The three conditions are tested and validated using a simulation model in the following section.

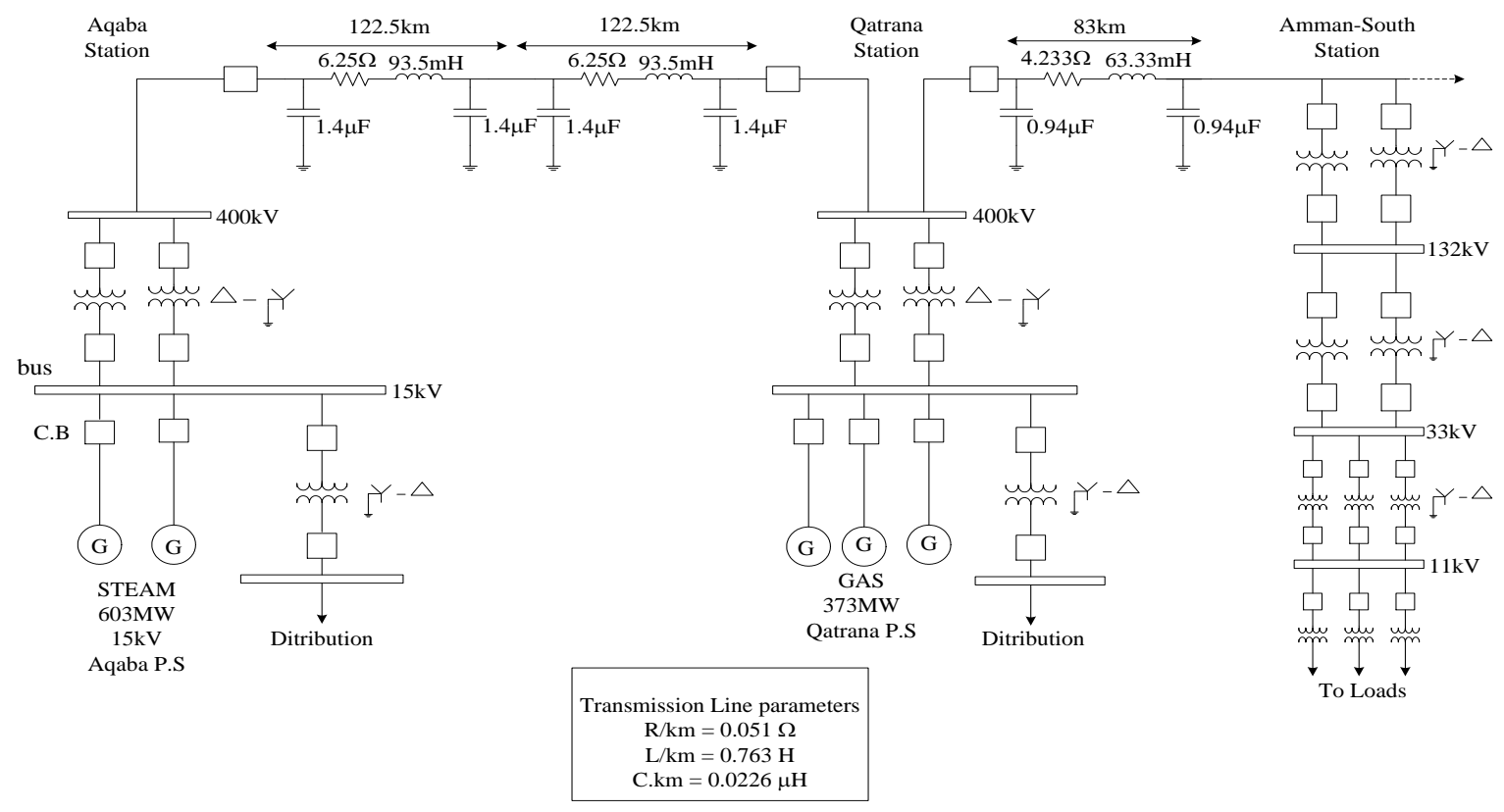

Figure 5. One line diagram of aqaba-qatrana- south amman power system

\section{RESULTS AND DISCUSSIONS}

In the proposed technique, the sinusoidal signal of the power system is sampled into a predefined number of samples. The sum $\left(\mathrm{V}_{\text {sum }}\right)$ and space vector $\left(\mathrm{V}_{\text {space }}\right)$ of the three load voltages are determined at each sample. The FDT will calculate the $\mathrm{V}_{\text {sum }}$ and $\mathrm{V}_{\text {space }}$ instantaneously. According to the three conditions discussed in Section 6, the FDT will detect the voltage unbalance in the system.

Figure 6 shows the simulation model of the AQSA Jordanian electrical power system and the proposed FDT. In this simulation, load changes are applied at the instant $t=0.1 \mathrm{sec}$ (i.e., at the sample number 100). Figure 7 (a) shows the response of the three load voltages due to a balanced change in the three-phase load. This change is caused by injecting $21.4 \%$ of the average inductive load current. The $\mathrm{V}_{\text {sum }}$ and $\mathrm{V}_{\text {space }}$ for this case are shown in Figures 7 (b) and 7 (c) respectively. It can be observed from Figure 7 that when the balanced change occurred, the $V_{\text {sum }}$ was zero at all instants of time and the $V_{\text {space }}$ settled at a fixed value. The results in Figure 7 verified Condition (1) introduced in section 6.

Figure 8 (a) shows the three load voltages due to unbalanced change in the three-phase loads. This change is caused by injecting $30 \%$ of the average inductive load current. The $\mathrm{V}_{\text {sum }}$ and $\mathrm{V}_{\text {space }}$ for this case are shown in Figures 8 (b) and 8 (c) respectively. It can be noted from Figure 8 that when the unbalanced change occurred, $\mathrm{V}_{\text {sum }}$ was zero at all instants of time, but $\mathrm{V}_{\text {space }}$ varied in sinusoidal form. The results in Figure 8 verified Condition (2) introduced in Section 6. Figures 9 (a) and 10 (a) show the three load voltages due to unbalanced changes in the power system caused by one line-to-earth and two lines-to-earth faults, respectively. As shown in Figures 9 (b), 9 (c), 10 (b) and 10 (c), both $\mathrm{V}_{\text {sum }}$ and $\mathrm{V}_{\text {space }}$ values varied in sinusoidal form. Thus, the results in Figures 9 and 10 verified Condition (3) given in Section 6. A short circuit between the two windings of the $11 \mathrm{kV}-380 \mathrm{~V}$ transformer is made and the results of the corresponding three load voltages, $\mathrm{V}_{\text {sum }}$, and $\mathrm{V}_{\text {space }}$ are shown in Figures 11 (a), 11 (b), and 11 (c), respectively. It is also 
observed that when the change occurred, both $\mathrm{V}_{\text {sum }}$ and $\mathrm{V}_{\text {space }}$ varied in sinusoidal form. The results in Figure 11 verified Condition (3) in the proposed FDT as introduced in section 6. According to the results shown in Figures 7-11, it is reasonable to conclude that the proposed FDT can detect the voltage unbalance in the three-phase power system quickly and accurately.

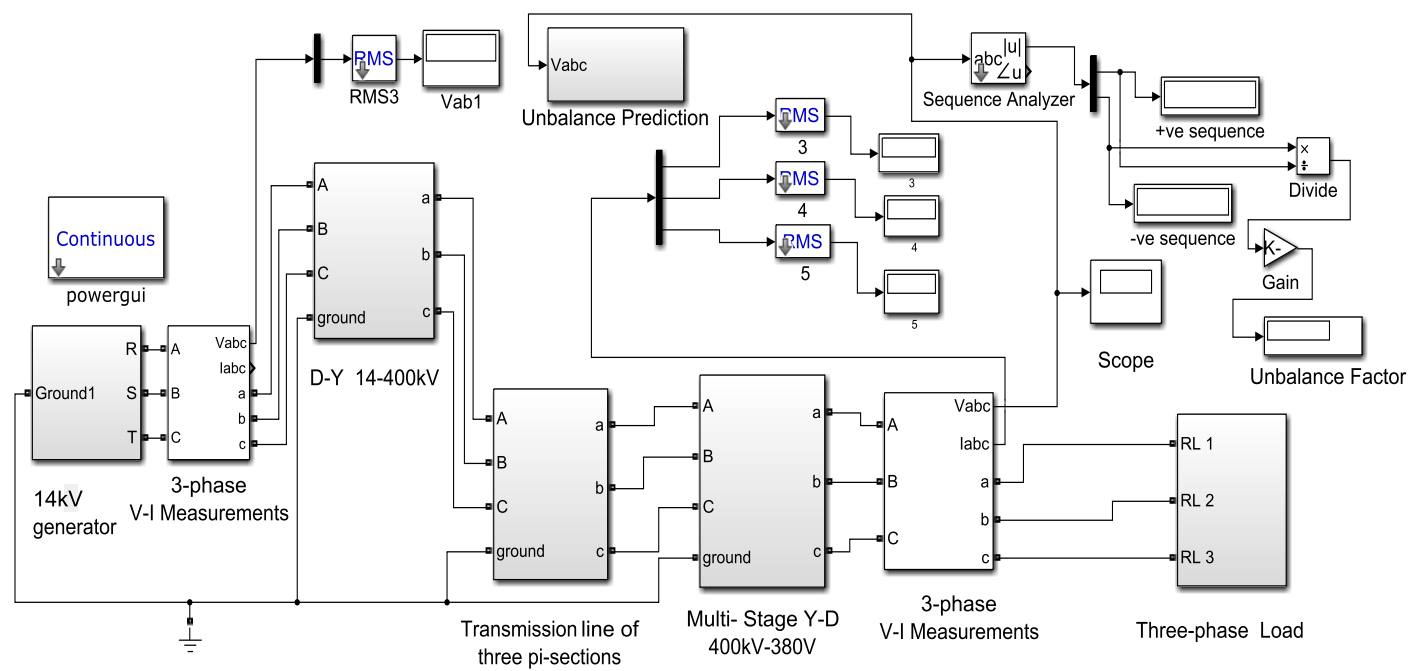

Figure 6. The simulation model of the AQSA electrical power system and the FDT

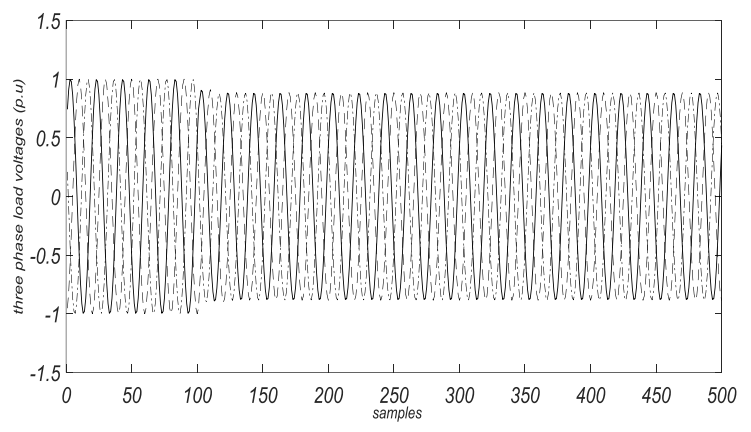

(a)

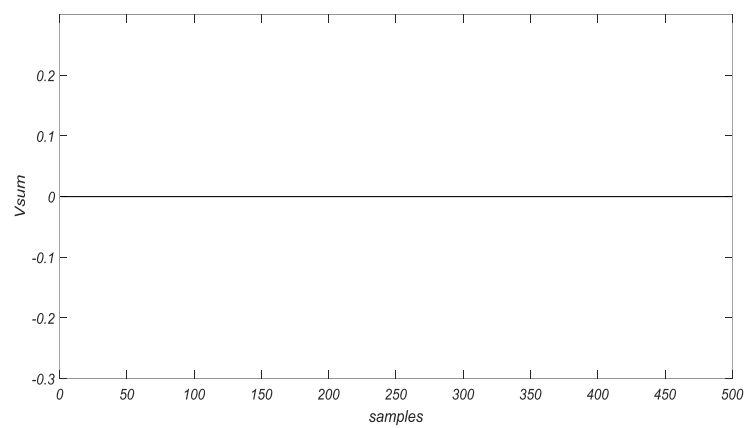

(b)

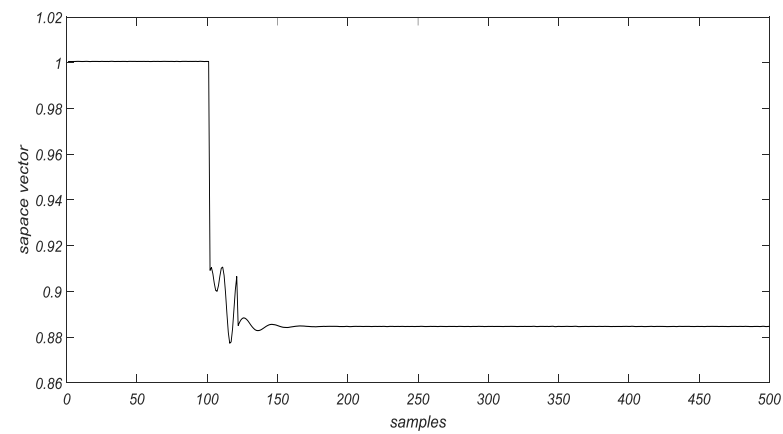

(c)

Figure 7. Results for a balanced change in the three-phase, caused by injection of $21.4 \%$ of the average inductive load current; (a) the p.u three load voltages, (b) the sum of the three p.u instantaneous load voltages

(c) the p.u space vector of the three instantaneous load voltages 


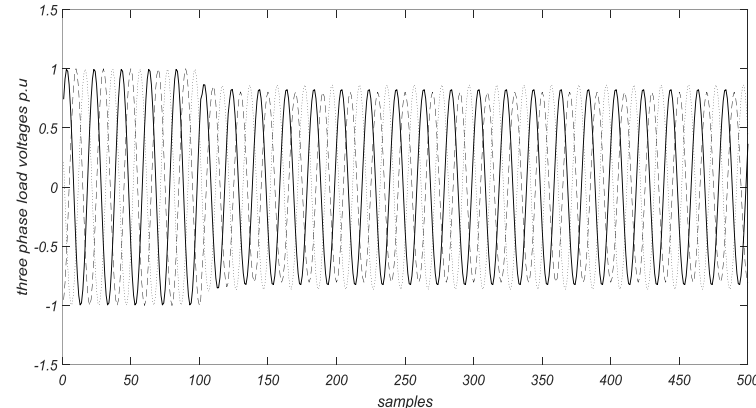

(a)

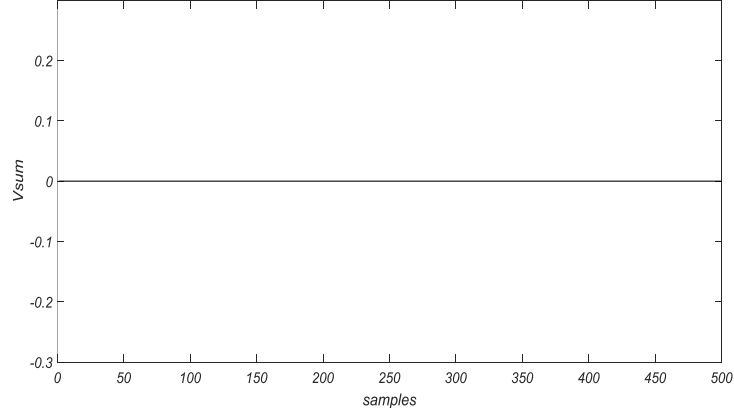

(b)

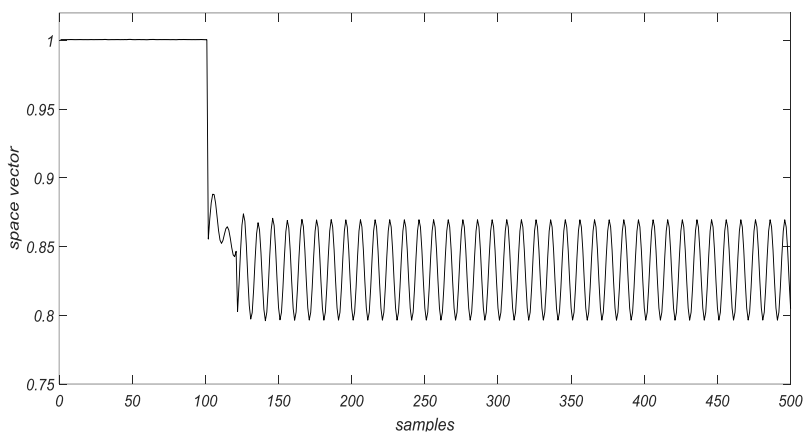

(c)

Figure 8. Results for an unbalanced change in the three-phase, caused by injection of $30 \%$ of the average inductive load current; (a) the p.u three load voltages, (b) the sum of the three p.u instantaneous load voltages, (c) the p.u space vector of the three instantaneous load voltages

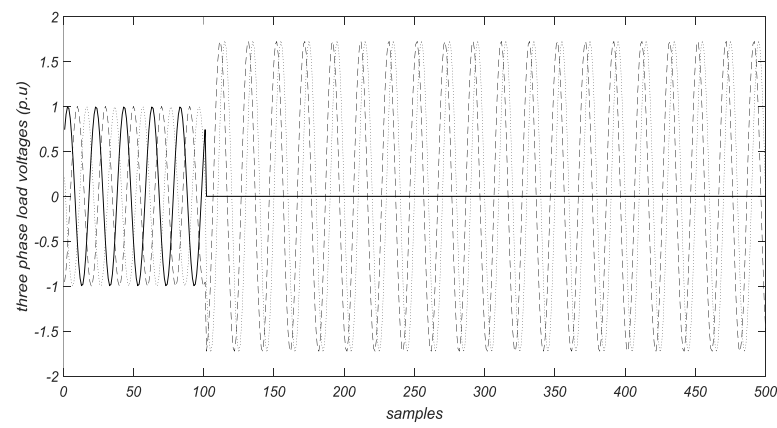

(a)

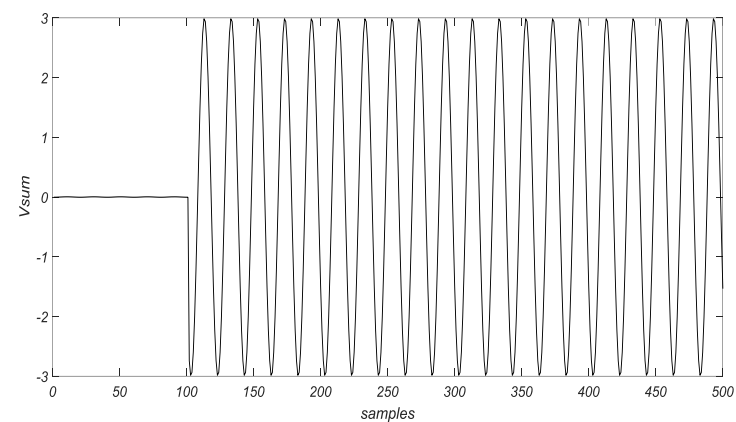

(b)

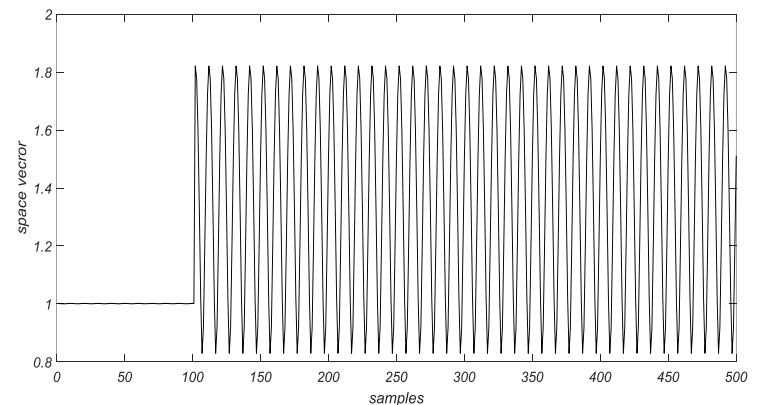

(c)

Figure 9. Results for unbalanced fault in the power system, due to one line-to-earth fault; (a) the p.u three load voltages, (b) the sum of the three p.u instantaneous load voltages, (c) the p.u space vector of the three instantaneous load voltages 


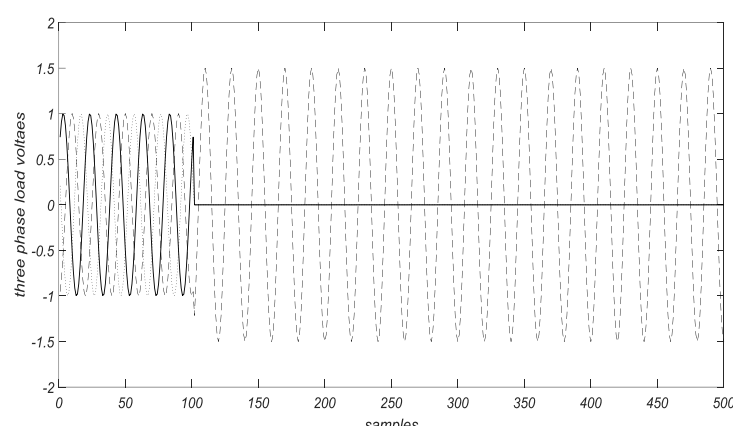

(a)

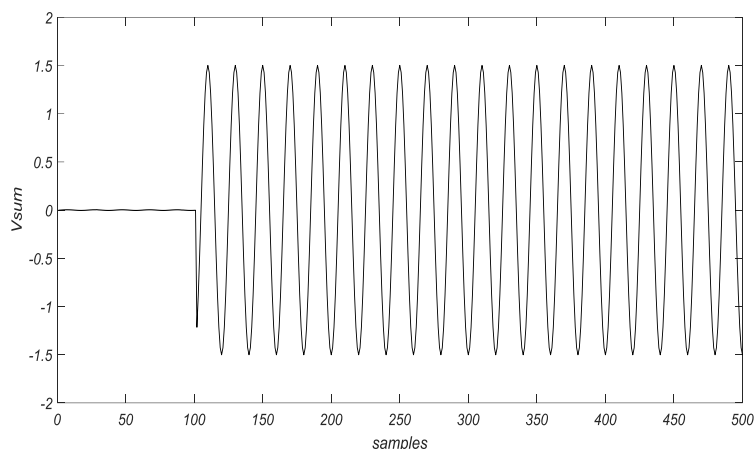

(b)

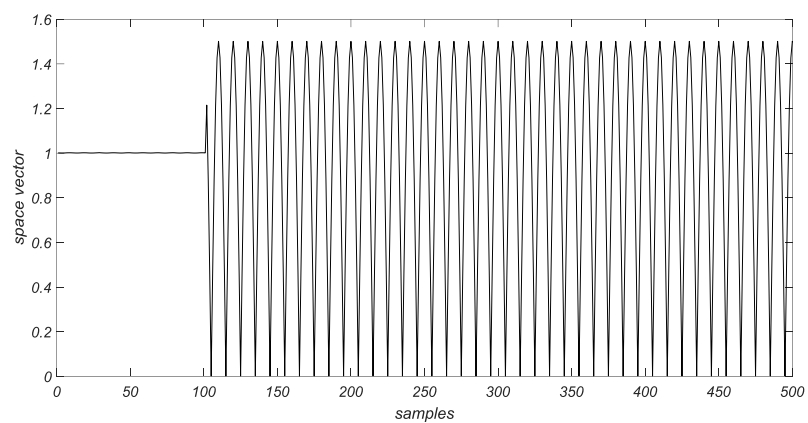

(c)

Figure 10. Results for unbalanced fault in the power system, due to two lines-to-earth faults; (a) the p.u three load voltages, (b) the sum of the three p.u instantaneous load voltages, (c) the p.u space vector of the three instantaneous load voltages

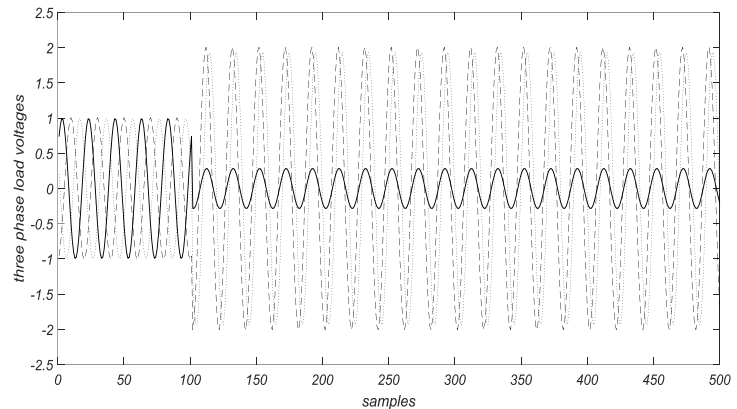

(a)

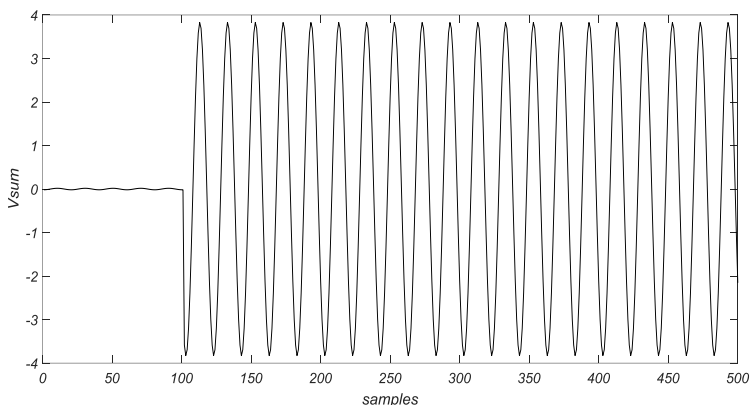

(b)

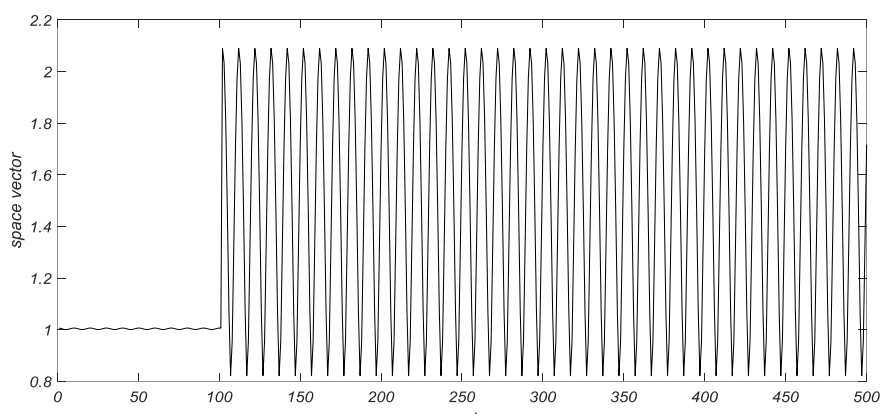

(c)

Figure 11. Results for unbalanced fault in the power system, due to the short circuit between two windings of the $11 \mathrm{kV}-380 \mathrm{~V}$ transformer; (a) the p.u three load voltages, (b) the sum of the three p.u instantaneous load voltages, (c) the sum of the three p.u instantaneous load voltages 


\section{CONTRIBUTION TO KNOWLEDGE}

Table 1 introduces a brief comparison between the detection methods mentioned in the literature and the proposed FDT. Accordingly, the contributions of knowledge in this paper are as follows: i) A novel technique is proposed to detect the voltage unbalance by using the space vector and the sum of the three load voltages. ii) The proposed technique has the superior ability among other techniques in detecting the voltage unbalance quickly within a quarter of the cycle time $(5 \mathrm{~ms})$. In other words, the proposed technique minimized the time duration required to detect the unbalanced voltages to $5 \mathrm{~ms}$ rather than $20 \mathrm{~ms}$. iii) The proposed technique has the ability to detect the all conditions of voltage unbalance accurately. iv) By reducing the time duration required to detect the unbalanced voltages, the dynamic response of the controller used to balance these voltages is enhanced noticeably.

Table 1. A comparison between different detection methods and the proposed FDT

\begin{tabular}{|c|c|c|c|c|}
\hline $\begin{array}{l}\text { Research } \\
\text { work }\end{array}$ & $\begin{array}{c}\text { The method used for } \\
\text { detection }\end{array}$ & $\begin{array}{c}\text { The time needed } \\
\text { for data collection } \\
\text { (50 Hz Ac power } \\
\text { system) }\end{array}$ & $\begin{array}{l}\text { The time needed to detect } \\
\text { the voltage unbalance ( } 50 \\
\text { Hz Ac power system) }\end{array}$ & Comments \\
\hline [36] & $\begin{array}{l}\text { Convert the three } \\
\text { voltages to a-b } \\
\text { stationary system } \\
\text { using Clark- } \\
\text { transformation }\end{array}$ & $\begin{array}{l}1 \text { complete cycle } \\
(20 \mathrm{~ms})\end{array}$ & $>10 \mathrm{~ms}$ & $\begin{array}{l}\text { The total time needed for data collection } \\
\text { and detecting the voltage unbalance is } \\
\text { more than } 30 \mathrm{~ms}\end{array}$ \\
\hline [37] & $\begin{array}{l}\text { Transform the } \\
\text { voltage phasors into } \\
\text { simple } \\
\text { trigonometric } \\
\text { equations }\end{array}$ & $\begin{array}{l}1 \text { complete cycle } \\
(20 \mathrm{~ms})\end{array}$ & $\leq 10 \mathrm{~ms}$ & $\begin{array}{l}\text { The total time needed for data collection } \\
\text { and detecting the voltage unbalance is } \\
\text { less than } 30 \mathrm{~ms}\end{array}$ \\
\hline [38] & $\begin{array}{l}\text { Calculate the } \\
\text { positive and } \\
\text { negative sequence } \\
\text { components }\end{array}$ & $\begin{array}{l}1 \text { complete cycle } \\
(20 \mathrm{~ms})\end{array}$ & $10 \mathrm{~ms}$ & $\begin{array}{l}\text { The total time needed for data collection } \\
\text { and detecting the voltage unbalance is } \\
\qquad 30 \mathrm{~ms}\end{array}$ \\
\hline [39] & $\begin{array}{l}\text { Use modified } \\
\text { mathematical } \\
\text { approach to } \\
\text { calculate modified } \\
\text { VUF based on zero } \\
\text { sequence } \\
\text { component }\end{array}$ & $\begin{array}{l}1 \text { complete cycle } \\
(20 \mathrm{~ms})\end{array}$ & $10 \mathrm{~ms}$ & $\begin{array}{l}\text { The total time needed for data collection } \\
\text { and detecting the voltage unbalance is } \\
\qquad 30 \mathrm{~ms}\end{array}$ \\
\hline [40] & $\begin{array}{c}\text { Calculate the VUF, } \\
\text { PVUR, and LVUR } \\
\text { to detect the voltage } \\
\text { unbalance }\end{array}$ & $\begin{array}{l}1 \text { complete cycle } \\
(20 \mathrm{~ms})\end{array}$ & $>10 \mathrm{~ms}$ & $\begin{array}{c}\text { The total time needed for data collection } \\
\text { and detecting the voltage unbalance is } \\
\text { more than } 30 \mathrm{~ms}\end{array}$ \\
\hline $\begin{array}{l}\text { The } \\
\text { proposed } \\
\text { technique }\end{array}$ & $\begin{array}{l}\text { Calculate the space } \\
\text { vector and the sum } \\
\text { of three voltages in } \\
\text { a discrete manner }\end{array}$ & $\begin{array}{l}4 \text { ms (The time } \\
\text { interval between } 5 \\
\text { consecutive } \\
\text { samples) }\end{array}$ & $1 \mathrm{~ms}$ & $\begin{array}{l}\text { The time needed for collecting data and } \\
\text { detecting the voltage unbalance is } 5 \mathrm{~ms} \\
\text { (a quarter of the cycle time) }\end{array}$ \\
\hline
\end{tabular}

\section{CONCLUSIONS}

A novel technique has been proposed to detect the voltage unbalance in the three-phase power system. The proposed FDT depends on measuring the three load voltages in a discrete manner. The FDT utilizes the $\mathrm{V}_{\text {sum }}$ and $\mathrm{V}_{\text {space }}$ to detect the unbalanced voltages at the load quickly and precisely. A simulation model for aqaba-qatrana-south amman (AQSA) Jordanian power system has been built and several test cases have been conducted to test and validate the capability of the proposed technique. The results have revealed a high performance of the proposed FDT in detecting the unbalanced voltages quickly within $5 \mathrm{~ms}$.

\section{REFERENCES}

[1] Y. Kim, "Development and Analysis of a Sensitivity Matrix of a Three-Phase Voltage Unbalance Factor," IEEE Transactions on Power Systems, vol. 33, no. 3, pp. 3192-3195, May 2018, doi: 10.1109/TPWRS.2018.2807980.

[2] P. T. Ogunboyo, R. Tiako and I. E. Davidson, "Effectiveness of Dynamic Voltage Restorer for Unbalance Voltage Mitigation and Voltage Profile Improvement in Secondary Distribution System," Canadian Journal of Electrical and Computer Engineering, vol. 41, no. 2, pp. 105-115, Spring 2018, doi: 10.1109/CJECE.2018.2858841.

[3] J. Saroha, "Harmonic and voltage unbalance compensation in an islanded microgrids using parallel neural digital filter," International Journal of Electronics Engineering, IET, vol. 10, issue 1, pp. 384-391, 2018. 
[4] T. Antic, T. Capuder, and M. Bolfek, "A Comprehensive Analysis of the Voltage Unbalance Factor in PV and EV Rich Non-Synthetic Low Voltage Distribution Networks," Energies, MPDI, vol. 14, no. 1, pp. 1-30, 2021, doi: $10.3390 /$ en 14010117.

[5] J. Huang and Z. Jiang, "Power Quality Assessment of Different Load Categories," Energy Procedia, vol. 141, pp. 345-351, 2017, doi: 10.1016/j.egypro.2017.11.041.

[6] D. Lineweber and S. McNulty, "The Cost of Power Disturbances to Industrial and Digital Economy Companies," Primen, EPRI's Consortium for Electric Infrastructure for a Digital Society CEIDS, 2001.

[7] H. K. M. Paredes, D. T. Rodrigues, J. C. Cebrian and J. P. Bonaldo, "CPT-Based Multi-Objective Strategy for Power Quality Enhancement in Three-Phase Three-Wire Systems Under Distorted and Unbalanced Voltage Conditions," IEEE Access, vol. 9, pp. 53078-53095, 2021, doi: 10.1109/ACCESS.2021.3069832.

[8] C. Okoli, B. Anyaka, C. Nwokedi, and V. Anya, "Application of Composite Method for Determining Fault Location on Electrical Power Distribution Lines," Journal of Electrical and Computer Engineering, Hindawi, vol. 2020, ID. 2836940, pp. 1-9, 2020, doi: 10.1155/2020/2836940.

[9] G. Wang, F. Gao, J. Liu, Q. Li and Y. Zhao, "Design consideration and performance analysis of a hybrid islanding detection method combining voltage unbalance/total harmonic distortion and bilateral reactive power variation," CPSS Transactions on Power Electronics and Applications, vol. 5, no. 1, pp. 86-100, March 2020, doi: 10.24295/CPSSTPEA.2020.00008.

[10] M. H. Albadi, A. S. Al Hinai, A. H. Al-Badi, M. S. Al Riyami, S. M. Al Hinai and R. S. Al Abri, "Unbalance in power systems: Case study,” IEEE International Conference on Industrial Technology (ICIT), 2015, pp. $1407-$ 1411, doi: 10.1109/ICIT.2015.7125294.

[11] G. Bao and S. Ke, "Load Transfer Device for Solving a Three-Phase Unbalance Problem Under a Low-Voltage Distribution Network," Energies, vol. 12, no. 15, pp. 1-18, 2019, doi: 10.3390/en12152842.

[12] P. Paranavithana and S. Perera, "Location of sources of voltage unbalance in an interconnected network," IEEE Power \& Energy Society General Meeting, pp. 1-6, 2009, doi: 10.1109/PES.2009.5275641.

[13] S. Omran, R. Broadwater, J. Hambrick, M. Dilek, C. Thomas, and F. Kreikebaum, "Load growth and power flow control with DSRs: Balanced vs unbalanced transmission networks," Electric Power Systems Research, Elsevier, vol. 145, pp. 207-213, 2017, doi: 10.1016/j.epsr.2017.01.012.

[14] Energy Tips: Motor System, "Eliminate Voltage Unbalance,” U. S. Department of Energy: Washington, 2012.

[15] B. Tomoiaga, M. Chindris, A. Sumper, R. V. Robles, and A. S. Andreu, "Distribution system reconfiguration using genetic algorithm based on connected graphs," Electric Power Systems Research, Elsiever, vol. 104, pp. 216-225, 2013, doi: 10.1016/j.epsr.2013.06.021.

[16] J. Ghaeb and J. Chebil, "Prediction of Voltage Unbalance Employing Space Vector Property," International Journal of Engineering Research and Development, vol. 12, no. 12, pp. 65-70, 2017.

[17] W. H. Kersting and W. H. Phillips, "Phase frame analysis of the effects of voltage unbalance on induction machines," IEEE Transactions on Industry Applications, vol. 33, no. 2, pp. 415-420, March-April 1997, doi: $10.1109 / 28.568004$

[18] D. Zhang, R. An and T. Wu, "Effect of Voltage Unbalance and Distortion on the Loss Characteristics of ThreePhase Cage Induction Motor," IET Electric Power Applications, vol. 12, no. 2, pp. 264-270, 2018, doi: 10.1049/ietepa.2017.0464.

[19] Ching-Yin Lee, "Effects of unbalanced voltage on the operation performance of a three-phase induction motor," IEEE Transactions on Energy Conversion, vol. 14, no. 2, pp. 202-208, June 1999, doi: 10.1109/60.766984.

[20] J. Driesen and T. Craenenbroeck, "Voltage Disturbances: Introduction to Unbalance," Copper Development Association, Katholieke Universiteit Leuven: Brussels, 2002.

[21] J. Thomas, P. S. Revuelta, A. P. Valles, and S. P. Litran, "Practical evaluation of unbalance and harmonic distortion in power conditioning," Electric Power Systems Research, Elsevier, vol. 141, pp. 487-499, 2016, doi: 10.1016/j.epsr.2016.08.012.

[22] J. Ghaeb and O. Aloquili, "High performance reactive control for unbalanced three-phase load," Europian Transaction in Electrical Power, vol. 20, no. 6, pp. 710-722, 2009, doi: 10.1002/etep.349.

[23] J. Martinez and G. Ramos, "Reactive power and harmonic distortion control in electric traction systems," IEEE/PES Transmission and Distribution Conference and Exposition: Latin America (T\&D-LA), 2010, pp. 190195, doi: 10.1109/TDC-LA.2010.5762881.

[24] J.H. Chen, W.-J. Lee and M.S. Chen, "Using a static VAr compensator to balance a distribution system IAS '96," Conference Record of the 1996 IEEE Industry Applications Conference Thirty-First IAS Annual Meeting, 1996, pp. 2321-2326 vol.4, doi: 10.1109/IAS.1996.563896.

[25] F. R. Quintela, J. M. G. Arevalo, R. C. Redondo, and N. R. Melchor, "Four-wire three-phase load balancing with Static VAr Compensators," International Journal of Electrical Power and Energy Systems, vol. 33, no. 3, pp. 562568, 2011, doi: 10.1016/j.ijepes.2010.11.010.

[26] S. Marx, D. Bender, "An Introduction to Symmetrical Components, System Modelling and Fault Calculation," 33th Annual HANDS-ON Relay School March 16-20, Washington State University Pullman, Washington, 2016.

[27] NEMA Standards, "Motors and Generators," 1993.

[28] IEEE Standard Dictionary of Electrical and Electronics Terms, in IEEE Std. 1996.

[29] "Definitions of Voltage Unbalance," IEEE Power Engineering Review, vol. 22, no. 11, pp. 49-50, Nov. 2002, doi: 10.1109/MPER.2002.4311797.

[30] J. Hu, K. Chen, T. Shen and C. Tang, "Analytical Solutions of Multilevel Space-Vector PWM for Multiphase Voltage Source Inverters,” IEEE Transactions on Power Electronics, vol. 26, no. 5, pp. 1489-1502, May 2011, doi: 10.1109/TPEL.2010.2084107. 
[31] S. Das, G. Narayanan and M. Pandey, "Space-Vector-Based Hybrid Pulsewidth Modulation Techniques for a Three-Level Inverter," IEEE Transactions on Power Electronics, vol. 29, no. 9, pp. 4580-4591, Sept. 2014, doi: 10.1109/TPEL.2013.2287095.

[32] T.-P. Chen, Y.-S. Lai and C.-H. Liu, "A new space vector modulation technique for inverter control," 30th Annual IEEE Power Electronics Specialists Conference. Record. (Cat. No.99CH36321), 1999, pp. 777-782 vol.2, doi: 10.1109/PESC.1999.785598.

[33] Y. Tadano, H. Shizunori, U. Shota, N. Masakatsu, S. Yukihiko, and I. Muneaki, "Direct Space Vector PWM Strategy for Matrix Converters with Reduced Number of Switching," IEEJ Transactions on Industry Applications, vol. 128, no. 4, pp. 550-559, 2008, doi: 10.1541/ieejias.128.550.

[34] J. A. Ghaeb, "Sampled data and space vector technique for static VAR compensation," 13th International MultiConference on Systems, Signals \& Devices (SSD), 2016, pp. 30-35, doi: 10.1109/SSD.2016.7473654.

[35] M. Sun, S. Demirtas and Z. Sahinoglu, "Joint Voltage and Phase Unbalance Detector for Three Phase Power Systems," IEEE Signal Processing Letters, vol. 20, no. 1, pp. 11-14, Jan. 2013, doi: 10.1109/LSP.2012.2226717.

[36] C. J. O'Rourke, M. M. Qasim, M. R. Overlin and J. L. Kirtley, "A Geometric Interpretation of Reference Frames and Transformations: dq0, Clarke, and Park," IEEE Transactions on Energy Conversion, vol. 34, no. 4, pp. 2070 2083, Dec. 2019, doi: 10.1109/TEC.2019.2941175

[37] H. Wen, D. Cheng, Z. Teng, S. Guo and F. Li, "Approximate Algorithm for Fast Calculating Voltage Unbalance Factor of Three-Phase Power System," IEEE Transactions on Industrial Informatics, vol. 10, no. 3, pp. 1799-1805, 2014, doi: 10.1109/TII.2014.2327485.

[38] T. Chen. C. Yang, and N. Yang, "Examination of the definitions of voltage unbalance," International Journal of Electrical Power and Energy Systems, vol. 49, pp. 380-385, 2013, doi: 10.1016/j.ijepes.2013.02.006.

[39] A. Nakadomari, Y. Y. Hong, P. Mandal, H. Takahashi, and T. Senjyu, "Optimization of Voltage Unbalance Compensation by Smart Inverter," Energies, vol. 13, no. 8, pp. 1-22, 2020, doi: 10.3390/en13184623.

[40] K. Girigoudar and L. Roald, "On the impact of different voltage unbalance metrics in distribution system Optimization," Electric Power System Research, Elsevier, vol. 189, no. 106656, 2020, doi: 10.1016/j.epsr.2020.106656.

[41] J. A. L. Ghijselen and A. P. M. V. Bossche, "Exact voltage unbalance assessment without phase measurements," IEEE Transactions on Power Systems, vol. 20, no. 1, pp. 519-520, 2005, doi: 10.1109/TPWRS.2004.841145.

[42] D. R. Sawitri, D. A. Asfani, M. H. Purnomo, I. K. E. Purnama and M. Ashari, "Early detection of unbalance voltage in three phase induction motor based on SVM," 9th IEEE International Symposium on Diagnostics for Electric Machines, Power Electronics and Drives (SDEMPED), 2013, pp. 573-578, doi: 10.1109/DEMPED.2013.6645772.

[43] M. Okelola and O. Olabode, "Detection of Voltage Unbalance on Three Phase Induction Motor Using Artificial Neural Network," International Journal of Emerging Trends in Engineering and Development, vol. 4,no. 8, pp. 1825, 2018, doi: 10.26808/rs.ed.i8v4.03.

[44] M. Alkayyati, and J. Ghaeb, "Hybrid PSO-ANN algorithm to control TCR for voltage balancing," IET Generation, Transmission \& Distribution, vol. 14, no. 5, pp. 863-872, 2020, doi: 10.1049/iet-gtd.2019.1246 .

[45] D. M. R.agab, J. A. Ghaeb, and I. A. Naimi, "Enhancing the response of thyristor-controlled reactor using neural network," International Transactions on Electrical Energy Systems, Wiley, vol. 29, no. 12, pp. 1-16, 2019, doi: 10.1002/2050-7038.12137.

[46] J. Grainger and W. Stevenson, "Power system analysis," 1994, New York: McGraw- Hill.

[47] Report of National Control Centre, Operation Department, National Electric Power Company, Jordan, 2017. 